\section{New Light on Jamoytius}

from our Vertebrate Palaeontology Correspondent

'THe $20 \mathrm{~cm}$ long fish Jamoytius kerwoodi White, from the Middle Silurian of Lesmahagow in Scotland, is one of the earliest well-known vertebrates. This fact alone makes it of potential interest in vertebrate phylogeny. The eyes are preserved as rather large pigmented spots, and there are also traces of what may be an extensive system of fin-folds. Prominent segmental structures which cover the trunk were interpreted as carbonized myomeres by White (Geol. Mag., 83, 89; 1946) in his original description, based on two specimens. This interpretation led him logically to the view that Jamoytius represented a stage in vertebrate evolution even earlicr than Amphioxus. Later writers, however, such as Stensiö (Traité de Zoologie, 13, 239; 1958), suggested that the segmental markings on the trunk were scales, not myomeres. Jamoytius was therefore included in the anaspid Agnatha and appeared to have lost most of its phylogenetic interest.

A new investigation of Jamoytius has now been completed by Ritchie (Palaeontology, 11, 21; 1968), who has discovered a new exposure of the Jamoytius horizon and collected a number of new specimens. Two features are of particular interest. Just as the eyes are preserved as pigmented stains (presumably the remains of sclerotic cartilages), so there is a ring-like stain at the anterior end of the body, which appears to be the remains of a cartilage which encircled the mouth. Ritchie agrees with earlier workers that the only plausible method of feeding for Jamoytius, with its round terminal mouth, is suctorial feeding of some kind. Associated with Jamoytius are large carbonaccous sheets of the problematic organism Dictyocaris, and Ritchie notes that these are often perforated by numerous circular holes, $3-5 \mathrm{~mm}$ across, which could have been caused by Jamoytius.

Equally significant are the remains of a simple branchial basket. This runs posteriorly from just behind the eye, and consists of a ladder-like framework with regularly spaced cross-bars. It seems likely that there were originally about 15 of these cross-bars, which presumably separated the openings of the gill pouches, as in cyclostomes.

Ritchie's specimens show clearly that the body was covered with scales. There appears to have been only a single very elongate scale per segment on each side of the body. The scales do not overlap, and may have been slightly separated from one another. Since they have become folded without fracturing, they seem to have been flexible, with little or no mineralization.

The trunk also contains traces of what Ritchie interprets as the intestine, but he can find no definite trace of a notochord. Very faint stains outside the limits of the scaling can be interpreted as the remains of lateral fin-folds and of a dorsal and an anal fin but, as Ritchie states, these are inconclusive. The tail fin appears to have been asymmetric, either heterocercal or, more probably, hypocercal.

Possessing a round suctorial mouth and a branchial basket, Jamoytius is structurally an almost ideal ancestor for the modern cyclostomes (the petromyzontids and the myxinoids), as Ritchie points out; the modern forms differ from it only in the absence of scales and paired fins. Physiological studies on osmotic regulation and salt content of the plasma have shown that the petromyzonts are secondarily adapted to life in fresh water, but that the myxinoids have always been marine. As described by Ritchie, the fauna associated with Jamoytius clearly indicates a marine environment. On this basis, also, it is therefore acceptable as the ancestor of both the living types of cyclostome. Though it has lost its former position as a possible ancestor of either Amphioxus or the Gnathostomes, Jamoytius has therefore retained its phylogenetic interest, though in a new context.

\section{Kites in the Everglades}

THE Florida everglade kite, Rostrhamus sociabili.s plumbeus, though reduced in numbers to hardly more than 20, still has a chance of survival if suitable marsh areas such as that in the Loxahatchee National Wildlife Refuge are preserved. This northernmost sub-species is found only in southern Florida, where it depends for its food on the freshwater snail, Pomacea paludis. It is one of the rarest birds in the United States; rarer even than the California condor and the whooping crane.

The position of the kite is assessed in a recently published report from the US Department of the Interior, Fish and Wildlife Service, Bureau of Sport Fisheries and Wildlife (Special Scientific ReportWildlife No. 109). The authors of the report are W. O. Stieglitz and R. L. Thompson. In the past, the range of the everglade kite extended from north-western Florida southward to A1gentina; west to north-western

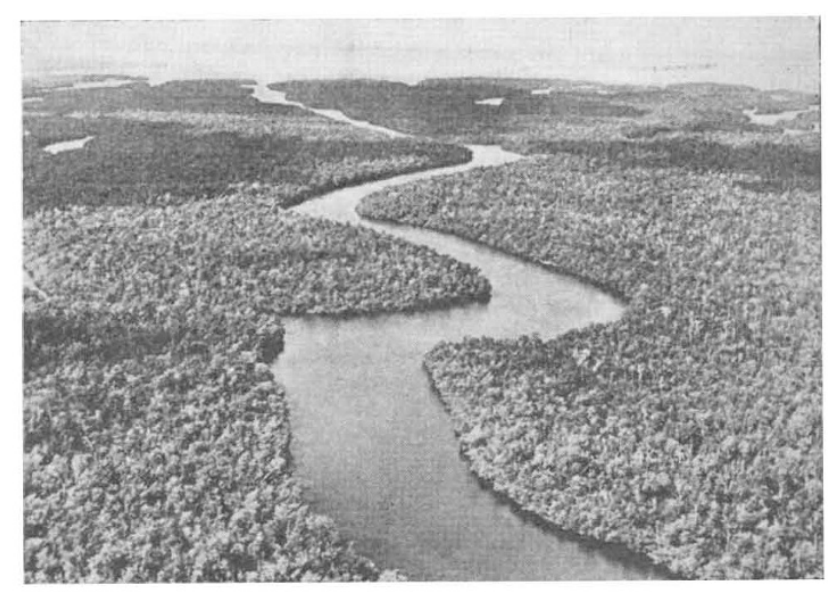

The Everglades, Florida.

Argentina, Ecuador, Colombia, Nicaragua, Guatemala; and eastward to eastern South America and Cuba. The sub-species found in the United States ( $R$. s. plumbeus) is confined to the peninsula of Florida.

The everglade kite was common in most of the freshwater marshes of Florida until about the early twenties. Much of the original habitat has, however, been reduced by flood control measures, grazing, citrus farming and urban development. The current known range of the kite in Florida includes the marshes of Lake Okeechobee, and conservation areas 1, 2 and 3 of the Central and Southern Florida Flood Control District. It is assumed that the populations of the everglade kite must have been much greater in the past, because the area of marshland available before human develop- 